\title{
Assessment of a pan-dermatophyte nested-PCR compared with conventional methods for direct detection and identification of dermatophytosis agents in animals
}

\author{
Fahimeh Piri $^{1,2}$ | Ali Zarei Mahmoudabadi ${ }^{1,2}$ | Ali Ronagh ${ }^{3}$ | Bahram Ahmadi ${ }^{4}$ \\ Koichi Makimura $^{5,6}$ | Ali Rezaei-Matehkolaei ${ }^{1,2}$ (D)
}

${ }^{1}$ Infectious and Tropical Diseases Research Center, Health Research Institute, Ahvaz Jundishapur University of Medical Sciences, Ahvaz, Iran

${ }^{2}$ Department of Medical Mycology, School of Medicine, Ahvaz Jundishapur University of Medical Sciences, Ahvaz, Iran

${ }^{3}$ Department of Clinical Sciences, Faculty of Veterinary Medicine, Shahid Chamran University of Ahvaz, Ahvaz, Iran

${ }^{4}$ Department of Medical Laboratory Sciences, School of Para-Medicine, Bushehr University of Medical Sciences, Bushehr, Iran

${ }^{5}$ Division of Clinical Laboratory Medicine, Graduate School of Medical Care and Technology, Teikyo University, Tokyo, Japan

${ }^{6}$ Laboratory of Space and Environmental Medicine, Graduate School of Medicine, Teikyo University, Tokyo, Japan

\section{Correspondence}

Ali Rezaei-Matehkolaei, Department of Medical Mycology, School of Medicine; Infectious and Tropical Diseases Research Center, Health Research Institute, Ahvaz Jundishapur University of Medical Sciences, Ahvaz, Iran.

Email: a.r.matehkolaie@gmail.com

Funding information

Ahvaz Jundishapur University of Medical Sciences, Ahvaz, Iran, Grant/Award Number: OG-95123; Japan Agency for Medical Research and Development (AMED), Grant/ Award Number: JP17fk0108208

\section{Summary}

Conventional direct microscopy with potassium hydroxide $(\mathrm{KOH})$ and culture were found to lack the ability to establish a fast and specific diagnosis of dermatophytosis. A pan-dermatophyte nested-PCR assay was developed using a novel primer pair targeting the translation elongation factor 1- $\alpha$ (Tef-1 $\alpha$ ) sequences for direct detection and identification of most veterinary relevant dermatophytes in animal samples suspected to dermatophytosis. A total of 140 animal skin and hair samples were subjected to direct microscopy, culture, and ITS-RFLP/ITS-sequencing of culture isolates for the detection and identification of dermatophytosis agents. Nested-PCR sequencing was performed on all the extracted DNAs using a commercial kit after dissolving the specimens by mechanical beating. Nested-PCR was positive in $90 \%$ of samples, followed by direct microscopy (85.7\%) and culture (75\%). The degree of agreement between nested-PCR and direct microscopy (94.4\%) was higher than with culture (83.3\%). In 105 culture-positive cases, the measures of agreement for the identification of dermatophytosis agents were as follows: $100 \%$ between nestedPCR sequencing and ITS-RFLP/ITS-sequencing and $63.8 \%$ between nested-PCR sequencing and culture. The developed nested-PCR was faster as well as more sensitive and specific than conventional methods for detection and identification of dermatophytes in clinical samples, which was particularly suitable for epidemiological studies.

\section{KEYWORDS}

animal, dermatophytosis, nested-PCR, Tef- $1 \alpha$

\section{1 | INTRODUCTION}

Dermatophytes are a group of keratinophilic fungi with global distribution that based on the newest proposed taxonomy consist of more than 50 species in the genera of Trichophyton, Microsporum, Epidermophyton, Nannizzia, Arthroderma, Lophophyton, and Paraphyton. ${ }^{1,2}$ Ecologically, 
(ringworm or tinea). ${ }^{3,4}$ Dermatophytosis is often enumerated as a selfhealing infection; however, animal dermatophytosis has attracted special attention in light of its contagiousness among pets and livestock, its zoonotic transmission to humans, its high cost of therapy, and lack of control measures. In livestock, especially cattle, sheep, and goat, dermatophytosis may lead to serious economic losses due to the negative impact on growth of affected animals, as well as their milk and meat production. ${ }^{5}$ Ringworm also leads to losses in the leather-related industries. ${ }^{5}$ Moreover, it has been reported as one of the most important morbidity factors in veterinary species. ${ }^{4}$ The accurate diagnosis of this infection and distinction of its causative agents are of great importance to track the source of dermatophytosis, to get appropriate treatment, and to better understand the epidemiological trends. ${ }^{6,7}$ Current standard approaches for diagnosis of human and animal dermatophytosis rely on conventional microscopic detection of fungal elements (arthroconidia and/or hyphae) in $\mathrm{KOH}$ preparation of clinical specimens as well as further morphological and biochemical analyses of in vitro cultures. ${ }^{7-10}$ With direct microscopy, the infection can be confirmed but its drawbacks are as follows: failure to distinguish between dermatophytic and nondermatophytic elements, inability to identify the causative agent at genus or species level, and numerous false-negative results due to lack of training. ${ }^{6,10,11}$ Culture in selective media is frequently associated with a poor sensitivity, mainly due to the development of a large variety of fungal or bacterial contaminants and also the presence of nonviable arthroconidia or mycelia in infected materials. ${ }^{4,5,12}$ Thus, a highly sensitive and specific method for fast and precise detection of dermatophytes would meet the practitioners' requirements and could significantly increase the management of cases suspected to dermatophytosis. Since late 1990s and with the advent of molecular biology, many attempts have been concentrated on the development of early and reliable PCR-based alternatives to direct microscopy and culture for the diagnosis of dermatophytosis. Some PCR-based methods targeting the internal transcribed spacer (ITS) regions, ${ }^{8,9}$ Chitin synthase (CHS), ${ }^{6,10}$ Topoisomerase II, ${ }^{13}$ and beta tubu$\operatorname{lin}^{11}$ genes are examples of these efforts for the direct detection of dermatophytes, mainly in human dermatophytosis. However, to date, there has been no molecular study devoted to evaluate fast and reliable procedures for the diagnosis of dermatophytosis in clinical animal materials. Our recent study revealed that translation elongation factor $1-\alpha($ Tef- $1 \alpha)$ was sufficiently polymorphic for the identification of dermatophytes up to the species level, and a pan-dermatophyte specific primer pair was developed for phylogenetic evaluation of dermatophytes species. ${ }^{14}$ In this study, we aimed to develop a novel set of primers amplifying a shorter DNA fragment from the internal sequence of Tef- $1 \alpha$ in the format of a nested-PCR assay for both detection and identification of dermatophytes directly in animal materials suspected to dermatophytosis.

\section{2 | MATERIALS AND METHODS}

\section{1 | Animal samples and mycological investigation}

The ethical approval (IR.AJUMS.REC.1395.403) was granted by the research ethics committee of Ahvaz Jundishapur University of
Medical Sciences, Ahvaz, Iran. Epidermal scales and hair samples from 140 symptomatic sheep, goat, cattle, dogs, cats, and horses were included in the study. The surface of lesion in symptomatic animal was gently wiped with $70 \%$ ethanol and the ethanol allowed to evaporate. Then skin scales and hairs were collected by scraping from the border of the lesion into a sterile Petri dish using a sterile scalpel blade. The first portion of each sample was microscopically investigated using $20 \% \mathrm{KOH}$ for the presence of branched hyphae and arthroconidia. Observation of the fungal active forms of branching hyphae or arthroconidia was considered as positive case. The other part was inoculated on Sabouraud's dextrose agar containing 0.05\% chloramphenicol and 0.5\% cycloheximide (Mycosel Agar; BD Difco, Sparks, MD, USA) and incubated at $28^{\circ} \mathrm{C}$ (and $37^{\circ} \mathrm{C}$ in cases suspected to T. verrucosum) for 1 month before being regarded as negative. Primary identification of isolates was carried out relying on the macro and micromorphological features of the colonies, ${ }^{15}$ which were then subjected to additional molecular identification.

\section{2 | Molecular identification}

All isolates from culture-positive samples were specified up to the species level by a PCR-RFLP assay targeting the ribosomal DNA internal transcribed spacer (ITS) regions. ${ }^{16}$ The genomic DNA was mechanically isolated from dermatophyte strains by bead beating of a small amount of each colony in a homogeniser (SpeedMill Plus; Analytik Jena, Jena, Germany) as described previously. ${ }^{17}$ ITS regions in each isolate were amplified using ITS1/ITS4 primer pair ${ }^{18}$ and subsequently digested with Mval restriction enzyme in accordance with the manufacturer's instructions (Thermo Fisher Scientific, Waltham, MA, USA). The restriction fragments were separated through electrophoresis on $2 \%$ agarose gel, and each isolate was identified based on a specific banding pattern described in the previous report. ${ }^{16}$

\subsection{DNA isolation from animal samples}

Given that there was no established protocol for the extraction of fungal DNA from infected animal scales, we developed a mechanical method supplemented with a commercial kit (Qiagen, Hilden, Germany) for this purpose. Approximately $300 \mu$ g of each skin fragment and hair sample was transferred to a $2 \mathrm{~mL}$, round-bottom, and cryogenic microtube and was subsequently crushed with an iron rod. Then, $300 \mu \mathrm{g}$ of $0.5 \mathrm{~mm}$ zirconium beads (Yasui Kikai Corporation, Osaka, Japan) was added to each sample and the tubes were frozen at $-80^{\circ} \mathrm{C}$ for 1 hour, immediately homogenised into powder using a bead beating machine (Multi-beads shocker ${ }^{\circledR}$; Yasui Kikai Corporation, Osaka, Japan) at 2100 rpm for 2 minutes. The milled samples were then treated with $300 \mu \mathrm{L}$ lysis buffer $(10 \mathrm{mmol} / \mathrm{L}$ Tris. $\mathrm{Cl} \mathrm{pH} \mathrm{8.0,} 10 \mathrm{mmol} / \mathrm{L}$ EDTA, $100 \mathrm{mmol} / \mathrm{L} \mathrm{NaCl}, 40 \mathrm{mmol} / \mathrm{L}$ DTT, $2 \%$ SDS, $250 \mu \mathrm{g} / \mathrm{mL}$ Proteinase K) and incubated at $56^{\circ} \mathrm{C}$ for 1 hour. Further extraction and purification of the genomic DNA from lysates was performed using QIAamp DNA mini kit (Qiagen) and the concentration of isolated DNAs was quantified with Qubit ${ }^{\circledR}$ 2.0 Fluorometer (Invitrogen, Carlsbad, CA, USA). 
Table 1. Dermatophyte standard strains and related Tef-1 $\alpha$ sequences used for evaluation of nested-PCR in the study and estimated size of Tef- $1 \alpha$ for each species

\begin{tabular}{|c|c|c|c|c|}
\hline Species & Strain number & $\begin{array}{l}\text { Estimated size of } \\
\text { Tef-1 } \alpha \text { (bp) }\end{array}$ & $\begin{array}{l}\text { ITS accession } \\
\text { number }\end{array}$ & $\begin{array}{l}\text { Tef-1 } \alpha \\
\text { accession } \\
\text { number }\end{array}$ \\
\hline \multirow[t]{2}{*}{ Microsporum canis } & CBS 130798 & \multirow[t]{2}{*}{522} & JN134120 & KM678151 \\
\hline & CBS 130811 & & JN134125 & KM678052 \\
\hline P. cookei & NBRC 7862 & 556 & JN134140 & KM678208 \\
\hline N. fulvua & CBS 130934 & 542 & KT155781 & KM678170 \\
\hline \multirow[t]{2}{*}{ N. gypsea } & IFO 5948 & \multirow[t]{2}{*}{551} & JN134133 & KM678196 \\
\hline & CBS 130820 & & JN134130 & KM678161 \\
\hline N. persicolor & NBRC 5975 & 536 & JN134144 & KM678207 \\
\hline \multirow[t]{2}{*}{ N. nana } & JCM 1907 & \multirow[t]{2}{*}{545} & JN134095 & KM678199 \\
\hline & CBS 321.61 & & DQ860795 & KM678084 \\
\hline \multirow[t]{2}{*}{ T. verrucosum } & CBS 563.50 & \multirow[t]{2}{*}{564} & - & KM678049 \\
\hline & CBS 554.84 & & Z98002 & - \\
\hline \multirow[t]{3}{*}{ T. mentagrophytes } & CBS 130815 & \multirow[t]{3}{*}{565} & JN133985 & KM678178 \\
\hline & CBS 130806 & & JN133989 & KM678180 \\
\hline & NBRC 5809 & & JN134101 & - \\
\hline \multirow[t]{3}{*}{ T. equinum } & CBS 270.66 & \multirow[t]{3}{*}{541} & KT155643 & KM678075 \\
\hline & CBS 109035 & & EF043279 & - \\
\hline & NBRC 31610 & & JN134108 & KM678061 \\
\hline T. benhamiae & JCM 1885 & 538 & JN134093 & KM678198 \\
\hline \multirow[t]{2}{*}{ T. simii } & CBS 520.75 & \multirow[t]{2}{*}{558} & KT155934 & KM678104 \\
\hline & CBS 417.65 & & KT155890 & KM678090 \\
\hline \multirow[t]{2}{*}{ A. unicinatum } & CBS 130926 & \multirow[t]{2}{*}{521} & KT155779 & - \\
\hline & IFO 13978 & & JN134092 & KM678197 \\
\hline
\end{tabular}

\section{4 | Pan-dermatophyte nested PCR}

In our previous study, a set of primer pair as EF-DermF (5-CACATTAACTTGGTCGTTATCG-3) and EF-DermR (5-CATCCTTGGAGATACCAGC-3) was introduced to amplify a 700-770 base pair fragment from Tef-1 $\alpha$ of dermatophytes for phylogenetic purposes. ${ }^{14}$ Here, we developed a novel set of primer, that is Rez-f (5'-TTGGTCGTTATCGGCCACG-3') and Rez-r (5'-WTGTACTTGGGGGTCTCG-3') to amplify a DNA fragment from the internal sequence of the first-round $P C R$ product. To develop this novel primer pair, the available Tef-1 $\alpha$ sequences belonging to the most common dermatophyte species causing animal dermatophytosis, that is Trichophyton mentagrophytes, T. verrusosum, T. benhamiae, T. simii, T. equinum, Microsporum canis, Nannizzia gypsea, N. nana, N.persicolor, N. fulva, Arthroderma uncinatum, and Paraphyton cookei were retrieved from GenBank (Table 1) and were included in the study. Primer design was performed by MEGA software.

The PCR mixture for first-round PCR contained $25 \mu \mathrm{L}$ of Taq DNA Polymerase 2× Master Mix Red (Ampliqon; Skovlunde, Denmark), 20 pmol of each primer (Bex Co., Ltd, Tokyo, Japan), $5 \mu \mathrm{L}$ of template DNA, and enough nuclease-free water up to a final volume of $50 \mu \mathrm{L}$. The time-temperature profile for PCR was as initial denaturation at $94^{\circ} \mathrm{C}$ for 5 minutes, followed by
35 cycles of denaturation at $94^{\circ} \mathrm{C}$ for 30 seconds, annealing at $62^{\circ} \mathrm{C}$ for 40 seconds, and extension at $72^{\circ} \mathrm{C}$ for 1 minute, with a final extension step at $72^{\circ} \mathrm{C}$ for 10 minutes. The PCR mixture for nested-PCR consisted of 20 pmol of Rez-f and Rez-r primers, a 1:20 dilution from the first PCR product, and the rest of the constituent was the same as the first-round reaction. The running conditions were similar to the first-round PCR, except for an annealing temperature of $58^{\circ} \mathrm{C}$ for 30 seconds. DNA of T. mentagrophytes CBS 130940 and double-distilled water were used as the positive and negative controls respectively. To document the amplification, $5 \mu \mathrm{L}$ of product from nested PCR was electrophoresed on $1.5 \%$ agarose gel.

\subsection{Validation of the specificity and sensitivity of nested-PCR}

To determine the analytical performance and specificity of nested-PCR assay, DNA of 22 reference strains representing the most important veterinary dermatophyte species (Table 1) and some saprophytic fungi, including Aspergillus flavus JCM 2061, A. fumigatus NBRC 4057, and Candida albicans ATCC 10231, were tested. In order to determine the lower limit of nested-PCR detection, serial dilutions (100, 50, 25, 10, 5, and $1 \mathrm{ng} / \mu \mathrm{L})$ from DNA of the T.mentagrophytes strain CBS 130815 were prepared in 
DNA extracts from three samples, which were negative in direct microscopy, culture, and nested-PCR. Five microlitres of each dilution was used in a 50- $\mu \mathrm{L}$ PCR reaction. The lowest DNA concentration leading to a positive nested-PCR was considered as the detection limit of the assay.

\subsection{Sequencing of ITS and nested-PCR products}

To verify the results of PCR-RFLP, all isolates from culturepositive samples were subjected to sequencing of the ITS r-DNA regions as gold standard for the identification of dermatophytes. Briefly, PCR amplification from each isolate was performed with the universal primer pair, that is $\mathrm{V} 9 \mathrm{G}^{19}$ and LS26. ${ }^{20}$ Subsequently, the products were sequenced in an $A B I$ Prism $^{\text {TM }} 3730$ genetic analyser (Applied Biosystems, Foster City, CA, USA) with the internal primers ITS1/ITS4. ${ }^{18}$ To confirm the specificity of the developed PCR, nested-PCR products from all reference strains and clinical samples were subjected to bidirectional sequencing by Rez-f and Rez-r primers as described. The sequences of samples were then compared with those of strains contained in the validated Online Dermatophyte Database of the Westerdijk Fungal Biodiversity Institute (formerly Centraalbureau voor Schimmelcultures CBS, Utrecht, The Netherlands) to identity each agent down to the species level.

\section{7 | Statistical analysis}

All data from the study, including the type of animal scale, results of diagnosis of dermatophytosis, and identification of dermatophyte agents by different methods were transferred to IBM SPSS Statistics (version 22). The likelihood ratios to get a positive result by each of direct microscopy, culture, and nested-PCR sequencing tests with regard to the type of animal scale were determined using Chi-Square test, and the level of statistical significance was set at $P<0.05$. The Kappa test was used to determine the degree of agreement between nested-PCR, direct smear, and culture for the diagnosis of dermatophytosis, as well as the agreement between nested-PCR sequencing and ITS-RFLP/sequencing for the identification of tinea agents.

\section{3 | RESULTS}

Out of 140 skin and hair samples from cattle (56), sheep (43), goats (12), cats (13), dogs (10), and horses (6) that were clinically suspected to dermatophytosis, 120 (85.7\%) and 105 (75\%) cases were, respectively, positive by direct microscopy and culture, and 121 (86.4\%) cases by both direct microscopy and culture (Tables 2 and 3). The positivity rates for dermatophytes detection in direct microscopy, culture, and nested-PCR methods were the highest for the samples from cattle (96.4\%-98.2\%; $P<0.05)$ and the lowest for the samples from cats and dogs (60.9\%-78.3\%). In primary screening of culturepositive isolates, based on the macroscopic and microscopic features of colonies, T. verrucosum (83) was found as the most frequent agent, followed by M. canis (9), T. mentagrophytes (7), and N. gypsea (1) (Table 3). In five cases, the isolates could not be identified due to lack of helpful characteristics (sterile hyphae). Restriction digestion and sequencing of ITS-rDNA products in 105 culture isolates led to identification of T. verrucosum (54) as the main causative agent, followed by T. mentagrophytes (38), M. canis (12), and N. gypsea (1). In nested-PCR, the Tef- $1 \alpha$ was successfully amplified from all dermatophyte reference strains and 126 out of 140 animal scales (90\%) but not from nondermatophyte species, yielding a single band of about 500 base pair (Figures 1 and 2). Totally, the highest rates of positivity for dermatophyte detection in increasing order were found by direct microscopy, culture, and nested-PCR (75\%, 85.7\%, and $90 \%$ respectively). This difference was statistically significant $(P<0.05)$. By statistical analysis with Chi-square test, the probability of direct microscopy, culture, and nested-PCR positivity was also found to be significantly higher in samples from cattle than other animals $(P<0.05)$ (Table 2). Considering direct microscopy as gold standard, sensitivity, positive, and negative predictive value of nested-PCR was found to be as $99.2 \%, 94.4 \%$, and $92.9 \%$ respectively. The query Tef- $1 \alpha$ sequences form dermatophyte reference strains and animal scales were searched against known sequences in GenBank, and the results of identification were exactly consonant with ITS-RFLP/ITSsequencing results. This led to the detection and identification of T. verrucosum (55) as the dominant agent, followed by T. mentagrophytes (53), M. canis (16), Nannizzia gypsea (1), and N. fulva (1). For the diagnosis of dermatophytosis, the degree of agreement between

\begin{tabular}{|lccc|}
\hline Examination method & Nested PCR $(+)$ & Nested PCR (-) & Total (\%) \\
\hline DM (+) & 119 & 1 & $120(85.7)$ \\
\hline DM (-) & 7 & 13 & $20(14.3)$ \\
\hline Total & 126 & 14 & $140(100)$ \\
\hline C (+) & 105 & 0 & $105(75)$ \\
\hline C (-) & 21 & 14 & $35(25)$ \\
\hline Total & 126 & 14 & $140(100)$ \\
\hline DM and/or C (+) & 120 & 1 & $121(86.4)$ \\
\hline DM and C (-) & 6 & 13 & $19(13.6)$ \\
\hline Total & 126 & 14 & $140(100)$ \\
\hline
\end{tabular}

Table 2. Comparison of direct microscopy, culture, and nested-PCR for diagnosis of dermatophytosis

C, culture; DM, direct microscopy. 
Table 3. Results of dermatophyte species identification in regards to the type of animal and method of identification

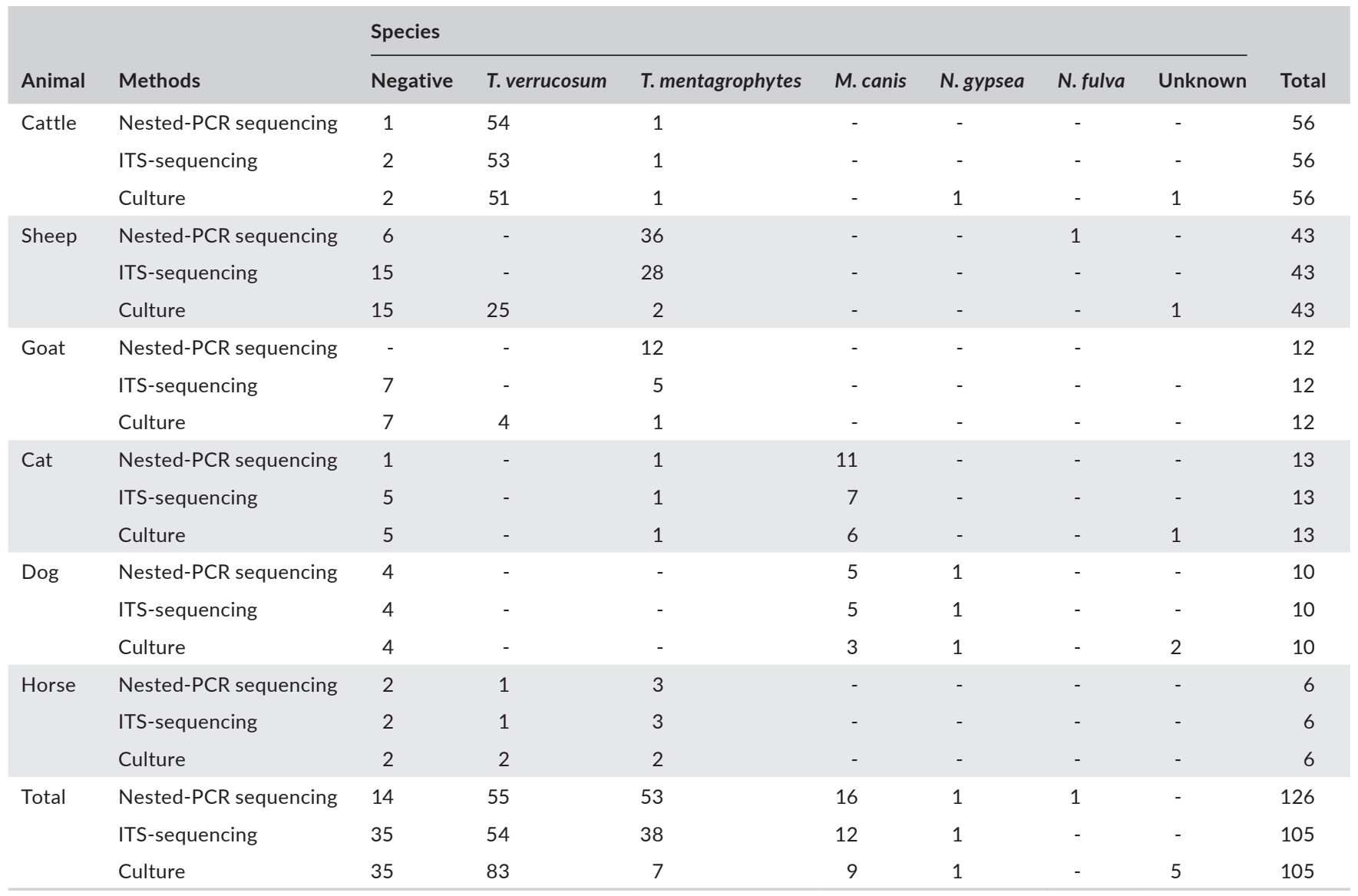

Figure 1. Results of Nested-PCR of Dermatophyte and Nondermatophyte Standard Strains. Lanes M: 100-bp DNA markers; lane 1; T. benhamiae (JCM 1885); lanes 2, 3; N. nana (JCM 1907 and CBS 321.61); lanes 4, 5: N. gypsea (IFO 5948 and CBS 130820); lane 6: A. flavus (JCM 2061); lane 7: A. fumigatus (NBRC 4057); lane 8: C. albicans (ATCC 10231); lanes 9, 10: T. simii (CBS 417.65 and CBS 520.75); lanes 11, 12: T. mentagrophytes (CBS 130815 and NBRC 5809); lanes 13, 14: M. canis (CBS 130798 and CBS 130811); lanes 15, 16: A. unicinatum (CBS 130926 and IFO 13978); lane 17: N. persicolor (NBRC 5975); lane 18: P. cookei (NBRC 7862); lanes 19, 20: T. equinum (CBS 270.66 and NBRC 31610); lanes 21, 22: T. verrucosum CBS 563.50 and (554.84). Lanes NC: nested-PCR negative controls

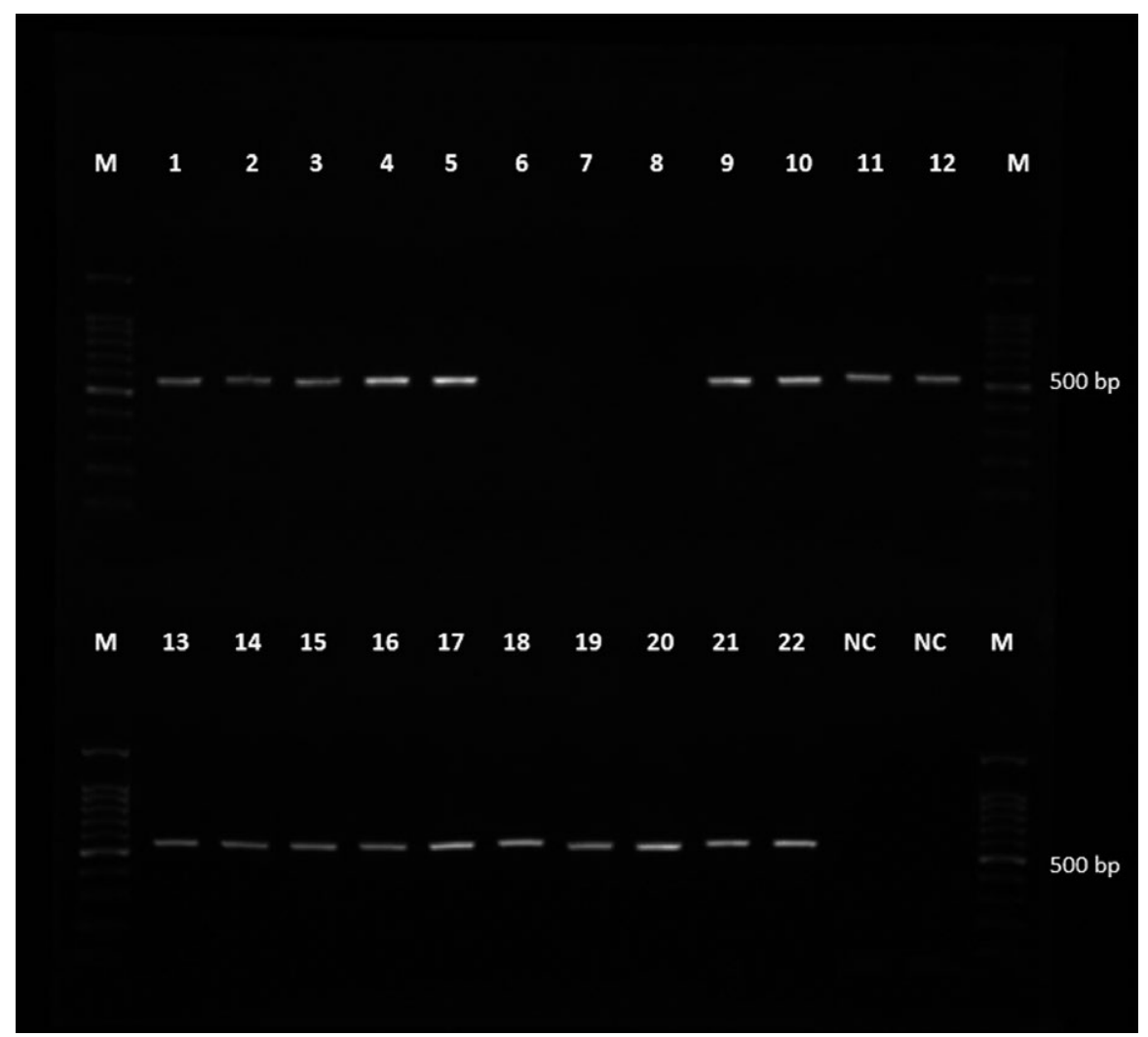




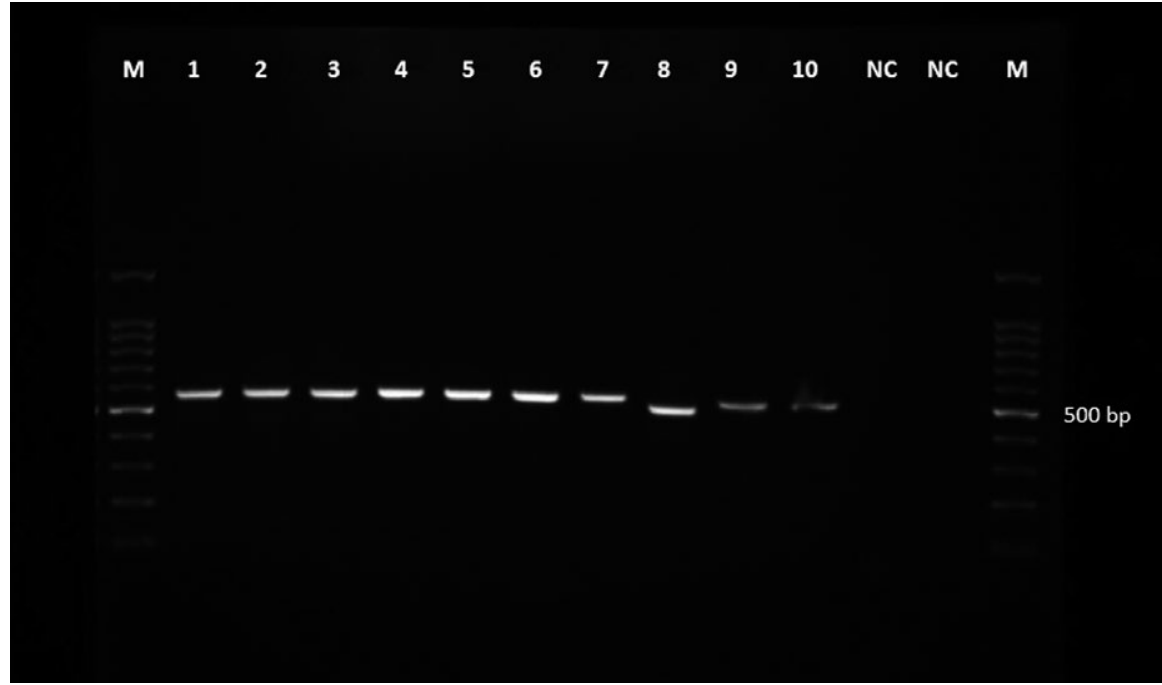

Figure 2. Results of Nested-PCR of Clinical Samples from Some Animals with Dermatophytosis. Lanes M: 100-bp DNA markers; lanes 1-4: T. mentagrophytes; lanes 5-7: T. verrucosum; lane 8: M. canis; lane 9: N. fulva; lane 10: N. gypsea. Lanes NC: nested-PCR negative controls
nested-PCR and direct microscopy (94.4\%) was higher than between nested-PCR and culture (83.3\%). On the other hand, nested-PCR was positive in $5 \%$ and $15 \%$ of cases negative for direct microscopy and culture respectively (Table 2). In 105 culture-positive cases, the level of consistency for the identification of dermatophytosis agents by kappa test was found to be $100 \%$ between nested-PCR and ITSsequencing (gold standard) and was $63.8 \%$ between nested-PCR and culture. The sensitivity of nested-PCR for the detection of dermatophyte DNA ranged from 5 to $100 \mathrm{ng} / \mu \mathrm{L}$.

\section{DISCUSSION}

A rapid and accurate diagnosis of animal dermatophytosis allows for the initiation of prompt antifungal therapy and prevention measures. ${ }^{6,7}$ In this study, nested-PCR was found to be more sensitive and specific than $\mathrm{KOH}$-microscopy and culture for detection and identification of dermatophytes. This is in agreement with Garg et $\mathrm{al}^{6}$, who developed a pan-dermatophyte nested-PCR targeting the chitin synthase 1 gene (CHS1) with a higher detection rate (79.6\%) than direct microscopy (63.4\%) and culture (25\%).

The conventional strategies for the diagnosis of dermatophytosis include direct microscopic investigation of $\mathrm{KOH}$-treated samples and culture. Direct microscopy is fast and inexpensive, but it lacks specificity and shows false-negative results in up to $15 \%$ of cases. ${ }^{21}$ Culture is a noteworthy adjunct to direct microscopic examination, which is essential for the identification of dermatophyte agents; however, the sensitivity of culture for diagnosis of dermatophytosis is low. ${ }^{22,23}$ Especially, in case of animal ringworm, this ratio may be much lower due to the high contamination rates of samples with environmental saprophytes. ${ }^{12}$ It is also known that some dermatophytes develop no characteristic feature in primary isolation, further complicating the results of culture for identification. ${ }^{24}$ In line with this fact, in five cases of this investigation, the culture isolates demonstrated no typical macroscopic or microscopic morphology for dermatophytes, whereas all cases were identified by nested-PCR.
Moreover, the zoophilic T. verrucosum species is well-known for its poor growth in primary cultures due to the need for specific incubation temperature $\left(37^{\circ} \mathrm{C}\right)$ and nutritional factors, and sometimes the observation of sensible growth is accompanied with difficulty even after long incubation. ${ }^{12}$ In countries where antifungal therapy is not allowed before the culture verification of dermatophytosis, additional sampling is needed for re-examination due to false-negative culture results, ${ }^{25}$ which leads to higher costs of sampling and inconvenience for the sick animal. Overall, species distinction of dermatophytes by culture is difficult and has low specificity. ${ }^{26}$

On the other hand, in some instances, the mycologist is encountered with a clinical sample that is negative microscopically but yields a positive result in culture. Therefore, the employed diagnostic technique is important. Taking into account this issue, new rapid and accurate methods, especially PCR-based approaches, have been developed for the diagnosis of dermatophytosis and identification of dermatophytes. ${ }^{6,9,25,27,28}$ Our developed nested-PCR assay was found to be specific and required no preculture step, which reduced the time to obtain the result from 2 to 8 weeks to 1 day. In contrast to the survey by Brillowska-Dabrowska et $\mathrm{al}^{25}$ and Paugam et al ${ }^{27}$, which found that the efficacy of PCR for the diagnosis of dermatophytosis was similar to custom direct microscopy and culture methods, our nested-PCR enabled both detection and identification of dermatophyte agents with more specificity and sensitivity. Detection of fungi in infected samples requires a high amount of extracted fungal DNA, which is not always obtained from clinical samples ${ }^{9}$; however, we developed a high-throughput DNA isolation method by combining a mechanical bead-beating procedure using a commercial kit.

In the study of Luk et $\mathrm{al}^{13}$, the detection rate of a single-round PCR targeting the Topoisomerase II gene was reported as $40 \%$ compared with $29.2 \%$ and $10 \%$ for direct microscopy and culture respectively. While the analytical sensitivity of PCR by Luk et al, was as 1:4 dilution of the primary DNA, our nested-PCR was positive in a DNA sample for which concentration ranged from 5 to $100 \mathrm{ng} / \mu \mathrm{L}$. In another investigation by Wisselink et $\mathrm{al}^{29}$, the detection rate of 
dermatophytes in clinical materials by real-time PCR (48.5\%) was superior to culture (26.9\%). In this study, the use of pan-dermatophyte primers in nested-PCR led to identification of all reference dermatophyte strains from 12 different species (Table 1). Unlike the study by Wisselink et $\mathrm{al}^{29}$, our nested-PCR was directly able to identify all the positive samples up to the species level and revealed no cross reaction between dermatophytes, medically important Aspergillus species, and C. albicans.

In UK and US practice, samples with positive direct microscopy, but negative culture results are considered as true positive. ${ }^{25}$ Given this fact, our nested-PCR yielded the highest positivity rate for dermatophytes, and the proportion of samples for which a dermatophyte was detected was increased from $75 \%$ (105) by culture to $90 \%$ (126) by nested-PCR (15\% false-negative culture results). Unlike some studies in which false-negative PCR results were found in a few specimens from which a dermatophyte had been isolated in culture, ${ }^{25,29,30}$ such results were not observed for nested-PCR in our study.

In view of specificity, proficiency testing indicates that species distinction of dermatophytes based on macro and micromorphometrics of isolates in culture is difficult and has a low specificity $(56 \%) .{ }^{26}$ This fact was reflected in the current survey where accuracy rate of identification by culture was $63.8 \%$ (67 out of 105). Contrary to the culture, nested-PCR assay displayed excellent diagnostic indices, with $100 \%$ specificity for identification of infectious agents when compared with ITS-sequencing as gold standard. Thus, the discordance between the data from culture and nested-PCR assay was significant (36.2\%), and one must inquire the reliability of culture as a method for the identification of dermatophyte species. The most plausible explanation for this matter refers to the recent alterations in the taxonomy of dermatophytes. As shown in the recent sequence-based investigations, ${ }^{17,31}$ the high degree of discrepancy between culture-based criteria and PCR-based methods for the identification of $T$. verrucosum and T. mentagrophytes isolates is due to the fact that some dermatophyte strains morphologically masqueraded as T.verrucosum are indeed the former T. verrucosum var. autotrophicum, which had been considered to be conspecific with zoophilic variant of $T$. interdigitale based on molecular data. ${ }^{32}$ These strains are morphologically similar to T. verrucosum, have some African and Asiatic sheep as host, and are again synonymised with the zoophilic T. mentagrophytes species in the most recent taxonomy. ${ }^{1}$ This issue signifies that contrary to the sequence-based methods, morphological criteria are difficult to adapt with taxonomic changes, leading to misidentification of many species. Regarding the fact that most of the skin scales in our study were from cattle and hair from cats/dogs, it can be hypothesised that the ability of PCR-based methods for tracking of dermatophytes in hair samples is lower than epidermal scales. Among 14 samples negative for nested-PCR, 13 samples were from symptomatic animals that had also negative results for direct microscopy and culture (Table 2). One explanation for this finding is that the clinical signs in such cases result from infections or factors other than dermatophytosis such as demodicosis, bacterial folliculitis, seborrhoeic dermatitis, ectoparasites, nonpruritic alopecia, and abrasions caused by rubbing on rough surfaces. ${ }^{5}$

The advantages of Tef- $1 \alpha$ nested-PCR assay are that it has a high detection rate, is much faster, specific, and less labourintensive than culture-based methods. Moreover, its material costs are almost the same as the costs for conventional direct microscopy and culture, but it has the possibility to obtain the result during one working day.

In conclusion, despite some limitations, the evaluation of nested-PCR targeting the Tef- $1 \alpha$ gene demonstrated that the test was robust and could enhance the direct detection of dermatophytes in pathological animal materials and drastically increased the specificity of dermatophyte identification compared to $\mathrm{KOH}$ microscopy and culture. Therefore, it can help the veterinarians to initiate the fast and accurate antifungal treatment, to disconnect the chain of infection transmission in human and animal communities, and to provide data for epidemiological trends of dermatophytes.

\section{ACKNOWLEDGEMENTS}

This work was a MSc thesis (Fahimeh Piri) and was supported by a grant (No. OG-95123) from Vice-Chancellor for Research Affairs of Ahvaz Jundishapur University of Medical Sciences, Ahvaz, Iran and in part by Japan Agency for Medical Research and Development (AMED) under Grant Number JP17fk0108208 (KM).

\section{CONFLICT OF INTEREST}

The authors have no conflicts of interest regarding the content of this paper.

\section{ORCID}

Ali Rezaei-Matehkolaei (iD http://orcid.org/0000-0002-3119-8342

\section{REFERENCES}

1. de Hoog GS, Dukik K, Monod M, et al. Toward a novel multilocus phylogenetic taxonomy for the dermatophytes. Mycopathologia. 2017;182(1-2):5-31.

2. Gräser $\mathrm{Y}$, Monod M, Bouchara JP, et al. New insights in dermatophyte research. Med Mycol. 2018;56(suppl_1):2-9.

3. Nenoff P, Krüger C, Ginter-Hanselmayer G, Tietz HJ. Mycology-an update: part 1: dermatomycoses: causative agents, epidemiology and pathogenesis. J Dtsch Dermatol Ges. 2014;12(3):188-209.

4. Bond R. Superficial veterinary mycoses. Clin Dermatol. 2010;28(2):226-236.

5. Chermette R, Ferreiro L, Guillot J. Dermatophytoses in animals. Mycopathologia. 2008;166:385-405.

6. Garg J, Tilak R, Singh S, et al. Evaluation of pan-dermatophyte nested PCR in diagnosis of onychomycosis. J Clin Microbiol. 2007;45(10):3443-3445.

7. Kupsch $\mathrm{C}$, Ohst $\mathrm{T}$, Pankewitz F, et al. The agony of choice in dermatophyte diagnostics-performance of different molecular tests and 
culture in the detection of Trichophyton rubrum and Trichophyton interdigitale. Clin Microbiol Infect. 2016;22(8):735.e11-7.

8. Bergmans AM, Van der Ent M, Klaassen A, Böhm N, Andriesse GI, Wintermans RG. Evaluation of a single-tube real-time PCR for detection and identification of 11 dermatophyte species in clinical material. Clin Microbiol Infect. 2010;16(6):704-710.

9. Bergman A, Heimer D, Kondori N, Enroth H. Fast and specific dermatophyte detection by automated DNA extraction and real-time PCR. Clin Microbiol Infect. 2013;19(4):E205-E211.

10. Emam SM, El-salam OH. Real-time PCR: a rapid and sensitive method for diagnosis of dermatophyte induced onychomycosis, a comparative study. Alexandria J Med. 2016;52(1):83-90.

11. Motamedi M, Mirhendi $\mathrm{H}$, Zomorodian $\mathrm{K}$, et al. Clinical evaluation of $\beta$-tubulin real-time Pcr for rapid diagnosis of dermatophytosis, a comparison with mycological methods. Mycoses. 2017;60(10):692-696.

12. Papini R, Nardoni S, Fanelli A, Mancianti F. High infection rate of Trichophyton verrucosum in calves from Central Italy. Zoonoses Public Health. 2009;56(2):59-64.

13. Luk NM, Hui M, Cheng TS, Tang LS, Ho KM. Evaluation of PCR for the diagnosis of dermatophytes in nail specimens from patients with suspected onychomycosis. Clin Exp Dermatol. 2012;37(3):230-234.

14. Mirhendi H, Makimura K, de Hoog GS, et al. Translation elongation factor 1- $\alpha$ gene as a potential taxonomic and identification marker in dermatophytes. Med Mycol. 2014;53(3):215-224.

15. De Hoog GS, Guarro J, Gené J, Figueras MJ. Atlas of Clinical Fungi, 3rd edn. Utrecht, The Netherlands: CD-ROM, CBS-KNAW Fungal Biodiversity Centre; 2011.

16. Rezaei-Matehkolaei A, Makimura K, Shidfar MR, et al. Use of singleenzyme PCR-restriction digestion barcode targeting the internal transcribed spacers (ITS rDNA) to identify dermatophyte species. Iran J Public Health. 2012;41(3):82-94.

17. Rezaei-Matehkolaei A, Rafiei A, Makimura K, Gräser Y, Gharghani M, Sadeghi-Nejad B. Epidemiological aspects of dermatophytosis in Khuzestan, southwestern Iran, an update. Mycopathologia. 2016;181(7-8):547-553.

18. White TJ, Bruns T, Lee S, Taylor J. Amplification and direct sequencing of fungal ribosomal RNA genes for phylogenetics. Chapter 38. Pages 315-322. In: PCR Protocols: a Guide to Methods and Applications (M. Innis, D. Gelfand, J. Sninsky and T. White, eds.). Academic Press, Orlando, Florida.

19. van den Ende AG, De Hoog G. Variability and molecular diagnostics of the neurotropic species Cladophialophora bantiana. Stud Mycol. 1999;43:151-162.

20. Masclaux F, Guého E, De Hoog GS, Christen R. Phylogenetic relationships of human-pathogenic Cladosporium (Xylohypha) species inferred from partial LS rRNA sequences. J Med Vet Mycol. 1995;33(5):327-338.

21. Liu D, Coloe S, Baird R, Pedersen J. Application of PCR to the identification of dermatophyte fungi. J Med Microbiol. 2000;49(6):493-497.
22. Clayton YM. Clinical and mycological diagnostic aspects of onychomycoses and dermatomycoses. Clin Exp Dermatol. 1992;17(s1):37-40.

23. Hay R. Literature review. Onychomycosis. J Eur Acad Dermatol Venereol. 2005;19(s1):1-7.

24. Weitzman I, Summerbell RC. The dermatophytes. Clin Microbiol Rev. 1995;8(2):240-259.

25. Brillowska-Dabrowska A, Nielsen SS, Nielsen HV, Arendrup MC. Optimized 5-hour multiplex PCR test for the detection of tinea unguium: performance in a routine PCR laboratory. Sabouraudia. 2010;48(6):828-831.

26. Bergmans AM, Schouls LM, Van Der Ent M, Klaassen A, Böhm $N$, Wintermans RG. Validation of PCR-reverse line blot, a method for rapid detection and identification of nine dermatophyte species in nail, skin and hair samples. Clin Microbiol Infect. 2008;14(8):778-788.

27. Paugam A, L'ollivier C, Viguié $C$, et al. Comparison of real-time PCR with conventional methods to detect dermatophytes in samples from patients with suspected dermatophytosis. J Microbiol Methods. 2013;95(2):218-222.

28. Li HC, Bouchara JP, Hsu MM, Barton R, Chang TC. Identification of dermatophytes by an oligonucleotide array. J Clin Microbiol. 2007;45(10):3160-3166.

29. Wisselink GJ, Van Zanten E, Kooistra-Smid AM. Trapped in keratin; a comparison of dermatophyte detection in nail, skin and hair samples directly from clinical samples using culture and real-time PCR. J Microbiol Methods. 2011;85(1):62-66.

30. Alexander CL, Shankland GS, Carman W, Williams C. Introduction of a dermatophyte polymerase chain reaction assay to the diagnostic mycology service in Scotland. Br J Dermatol. 2011;164(5):966-972.

31. Abastabar M, Rezaei-Matehkolaei A, Shidfar MR, et al. A molecular epidemiological survey of clinically important dermatophytes in Iran based on specific RFLP profiles of beta-tubulin gene. Iran J Public Health. 2013;42(9):1049-1057.

32. Gräser $Y$, Scott J, Summerbell R. The new species concept in dermatophytes-a polyphasic approach. Mycopathologia. 2008;166(5-6):239.

How to cite this article: Piri F, Zarei Mahmoudabadi A, Ronagh A, Ahmadi B, Makimura K, Rezaei-Matehkolaei A. Assessment of a pan-dermatophyte nested-PCR compared with conventional methods for direct detection and identification of dermatophytosis agents in animals. Mycoses. 2018;00:1-8. https://doi.org/10.1111/myc.12821 